\title{
Meconium stained liquor and perinatal outcome
}

\author{
Aruna Biradar, Shreedevi Kori*, Neelamma Patil, S. R. Mudanur
}

Department of Obstetrics and Gynecology, Shri B. M. Patil Medical College, Vijayapur, Karnataka, India

Received: 04 October 2018

Accepted: 01 November 2018

\section{*Correspondence:}

Dr. Shreedevi Kori,

E-mail: shree_kori@yahoo.com

Copyright: (c) the author(s), publisher and licensee Medip Academy. This is an open-access article distributed under the terms of the Creative Commons Attribution Non-Commercial License, which permits unrestricted non-commercial use, distribution, and reproduction in any medium, provided the original work is properly cited.

\section{ABSTRACT}

Background: The aim of this study is to know the association between the meconium stained amniotic fluid and its association with the perinatal outcome.

Methods: All the patients coming to present hospital for delivery with meconium stained liquor during the study period were included in the study.

Results: 163 cases with meconium stained liquor (MSAF) were included in the study, 124(76.1\%) and 39(23.9\%) had thin and thick MSAF respectively. Among these cases, thick MSAF was more associated with high fetal heart rate (FHR) variability ( $p$ value- 0.030$)$, associated with increased rate of operative interference $(64.1 \%$; $p$ value- 0.001$)$, abnormal Apgar score (p value-0.003 at $1 \mathrm{~min}$ and 0.001 at $5 \mathrm{~min}$ ) and increased neonatal intensive care unit (NICU) admission $(33.3 \%$; $\mathrm{p}$ value $-<0.001)$.

Conclusions: Present study showed that thick meconium is associated with more complications like increased operative interference, birth asphyxia, meconium aspiration syndrome, low Apgar score, prolonged NICU stay and overall increased perinatal mortality compared to thin meconium stained liquor. As the gestational age increased the incidence of meconium increased and a greater number of thick meconium had abnormal CTG.

Keywords: MAS (meconium aspiration syndrome), MSAF (meconium stained amniotic fluid), NICU (neonatal intensive care unit)

\section{INTRODUCTION}

Meconium in Greek means Opium or Poppy like substances, which leads to increased sleepiness of foetus in mother's womb. Prevalence of meconium stained amniotic fluid (MSAF) is $12-16 \%$ of all the deliveries. ${ }^{1-3}$ In utero passage of meconium may simply represent the normal gastro intestinal maturation or may indicate an acute or chronic hypoxic event, thereby making it a warning sign of foetal compromise. ${ }^{4}$

Meconium in utero is associated with a poor perinatal outcome such as low Apgar score, chorioamnionitis, increased rate of Neonatal intensive care unit (NICU) admission and perinatal death..$^{5}$ Meconium passage is a normal event programmed within first 24-48 hours after delivery. Fetomaternal stress factors like hypoxia and infection lead to meconium passage in utero in near term foetuses, leading to perinatal morbidity and mortality. ${ }^{6}$ Even though the meconium appears very early in the foetal intestine in utero, it is not seen in amniotic fluid before 38 weeks of gestation age ${ }^{6}$ Detection of MSAF is associated with abnormal FHR, so once the MSAF is detected, continuous FHR monitoring is needed as is associated with abnormal foetal outcome. Meconium aspiration into the neonatal lungs, is associated with clinical entities ranging from respiratory distress to severe respiratory compromise thus leading to significant increase in perinatal morbidity and mortality.

MSAF is associated with both maternal and foetal risk factors. Maternal factors include hypertension, 
gestational diabetes mellitus, maternal chronic respiratory or cardiovascular diseases, post term pregnancy, preeclampsia and eclampsia. Foetal factors include oligohydramnios, foetal growth restriction and poor bio physical profile. ${ }^{8}$ MSAF is associated with increased risk of operative interference in terms of instrumental delivery or caesarean section and increased rate of neonatal resuscitation and meconium aspiration syndrome (MAS). ${ }^{9}$

Approximately $10 \%$ of all the pregnancies have MASF, out of which $5 \%$ i.e., 1 in 200 cases goes for meconium aspiration into lungs of foetus or neonate leading to severe respiratory distress and meconium aspiration syndrome (MAS). ${ }^{10}$

MAS can cause or contribute to neonatal death. Around one third of all the cases of MSAF, in which aspiration occurs can develop long term respiratory compromise. ${ }^{11}$ MSAF is a clinical diagnosis with no confirmatory test. ${ }^{12}$ Various methods which may help to detect MSAF include amnioscopy during early labour, oropharyngeal suction and endotracheal intubation after birth. Perinatal morbidity and mortality associated with MSAF can be decreased by identifying the high-risk factors in antenatal period and careful decisions are made about the timing and mode of delivery and vigilant monitoring of the labour. ${ }^{13}$

This study was carried out to know the correlation of MSAF with perinatal outcome. Also, to know the difference between thin and thick MSAF on fetal outcome. In relation with stage and mode of delivery and antenatal complications. Authors also correlated the association between abnormal CTG during labour and the association with detection of MSAF to delivery interval.

\section{METHODS}

After obtaining ethical clearance this prospective observational study was carried out from January 2014 to June 2014. The study was done on the patients coming to labour ward at Shri B. M. Patil Medical College and Research Centre, Vijayapur, India.

\section{Inclusion criteria}

- Study included all the pregnant women $>37$ weeks of gestational age with meconium stained amniotic fluid, singleton pregnancy and cephalic presentation.

\section{Exclusion criteria}

- Excluded cases were gestational age <37 weeks, previous caesarean section, multiple pregnancy, noncephalic presentations (breech/ transverse and compound presentation) and any known congenital anomalies.
A total of 162 cases were enrolled in the study after taking the informed consent from the patients. Detailed history was taken, and clinical examination done. CTG was done on admission and fetus was monitored with electronic fetal monitoring. Patients were graded as thin and thick MSAF found at the time of spontaneous rupture of membranes or by artificial rupture of membranes (ARM). Relation of thick or thin meconium was noted in correlation with maternal age, parity, stage of labour (i.e., latent or active), FHR pattern by cardiotocography, antenatal complications, mode of delivery (vaginal/ caesarean section) Apgar score at $1 \mathrm{~min}$ and $5 \mathrm{~min}$ of birth, NICU admissions and perinatal outcome were noted. Newborns admitted in NICU were followed up till discharge from the hospital.

With incidence of $12 \%$ of meconium stained amniotic fluid out of all deliveries at $95 \%$ confidence interval and \pm 5 margin of error the sample size is 162 was required to be studied according to statistical analysis $\left\{n=Z \alpha^{2} p(1-\right.$ p) $\left./ d^{2}\right\}$.

\section{RESULTS}

Total of 1620 women delivered during the study period, out of which 162 meconium stained amniotic fluid were noted and their association with perinatal outcome was analysed. Out of $162,39(23.9 \%)$ had thick MSAF and $124(76.1 \%)$ had thin MSAF respectively (Table 1). There was no significant difference seen between parity and MSAF. In both primigravida and multigravida incidence of thin MSAF was more compared to thick meconium (Table 1).

Table 1: Comparison of gravidity/gestational age/ stage of labour with MSAF.

\begin{tabular}{|c|c|c|c|}
\hline Parameters & $\begin{array}{l}\text { Thick } \\
\text { MSAF }\end{array}$ & $\begin{array}{l}\text { Thin } \\
\text { MSAF }\end{array}$ & P value \\
\hline Primigravida & $18(46.2 \%)$ & $49(39.5 \%)$ & \multirow{2}{*}{0.462} \\
\hline Multigravida & $21(53.8 \%)$ & $75(60.5 \%)$ & \\
\hline \multicolumn{3}{|c|}{ Gestational age } & \multirow{4}{*}{0.109} \\
\hline$<37$ weeks & $4(10.3 \%)$ & $3(2.4 \%)$ & \\
\hline $37-40$ weeks & $9(23.1 \%)$ & $32(25.8 \%)$ & \\
\hline$\geq 40$ weeks & $26(66.7 \%)$ & $89(71.8 \%)$ & \\
\hline \multicolumn{3}{|c|}{ Stage of labour } & \multirow{3}{*}{$0.020 *$} \\
\hline$<4 \mathrm{~cm}$ & $17(43.6 \%)$ & $30(24.2 \%)$ & \\
\hline$>4 \mathrm{~cm}$ & $22(56.4 \%)$ & $94(75.8 \%)$ & \\
\hline
\end{tabular}

Out of 162 cases 115 cases having MSAF were of gestational age $\geq 40$ weeks and a greater number of cases were having thin MSAF (89 cases) (Table 1). Latent labour had $17 \& 30$ cases respectively in thick and thin MSAF. Active stage had 22 and 94 cases respectively in thick and thin MSAF, showing statistically significant difference with $\mathrm{p}$ value of 0.020 (Table 1). 
Table 2: Parameters assessed for neonatal outcome.

\begin{tabular}{|c|c|c|c|}
\hline $\begin{array}{l}\text { Outcome } \\
\text { measured }\end{array}$ & $\begin{array}{l}\text { Thick } \\
\text { MSAF }\end{array}$ & $\begin{array}{l}\text { Thin } \\
\text { MSAF }\end{array}$ & P-value \\
\hline $\begin{array}{l}\text { Meconium } \\
\text { aspiration } \\
\text { syndrome } \\
\text { (MAS) }\end{array}$ & $2(5.1 \%)$ & 0 & $0.011^{*}$ \\
\hline \multicolumn{4}{|l|}{ APGAR score } \\
\hline At 1 min (mean) & 6.4 & 6.8 & $0.003 *$ \\
\hline At 5 min (mean) & 8.3 & 8.8 & $0.001 *$ \\
\hline \multicolumn{4}{|l|}{ NICU stay } \\
\hline$\leq 24$ hour & $26(66.7 \%)$ & $116(93.5 \%)$ & $<0.001 *$ \\
\hline$\geq 24$ hour & $13(33.3 \%)$ & $8(6.5 \%)$ & \\
\hline
\end{tabular}

After delivery the Apgar score at $1 \mathrm{~min}$ and $5 \mathrm{~min}$ were noted and it was highly significant when compared with thin and thick MSAF as shown in Table 2. The number of fetus diagnosed with meconium aspiration syndrome (MAS) in our study were only $2(5.1 \%$ ) with thick MSAF with $\mathrm{p}$ value of 0.011 , which is highly significant (Table 2).

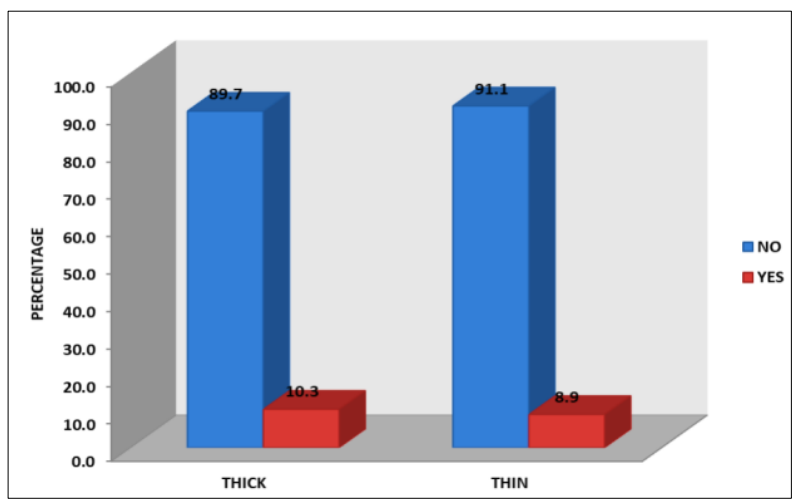

Figure 1: Antenatal complications association with MSAF.

There was no case with thin MSAF with meconium aspiration syndrome in our study. Of the 162 deliveries, 21 babies were admitted in NICU for $>24$ hours of which 13 and 8 with thick and thin MSAF respectively which was also highly significant with $\mathrm{p}$ value of $<0.001$ (Table 2).

Table 3: Association of NST with thick and thin MSAF.

\begin{tabular}{|c|c|c|c|c|c|}
\hline \multirow{2}{*}{$\begin{array}{l}\text { Non-stress } \\
\text { test (NST) }\end{array}$} & \multicolumn{2}{|c|}{ Thick } & \multicolumn{2}{|c|}{ Thin } & \multirow{2}{*}{ p value } \\
\hline & $\mathbf{N}$ & $\%$ & $\mathbf{N}$ & $\%$ & \\
\hline Normal & 12 & 30.8 & 69 & 55.6 & \multirow{3}{*}{$0.007 *$} \\
\hline Abnormal & 27 & 69.2 & 55 & 44.4 & \\
\hline Total & 39 & 100 & 124 & 100 & \\
\hline
\end{tabular}

Only 10 cases in our study had antenatal complications like pregnancy induced hypertension, pre-eclampsia, eclampsia, partial HELLP syndrome and moderate to severe anaemia. But the association of these complications with MSAF was not significant (Figure 1).

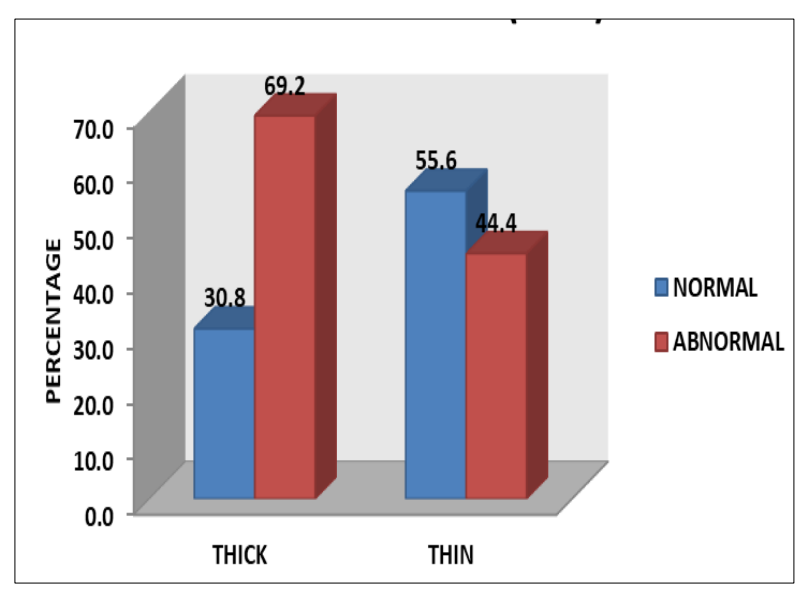

Figure 2: Association of MSAF with non-stress test.

Table 4: Mode of delivery according to meconium.

\begin{tabular}{|c|c|c|c|c|c|}
\hline \multirow{2}{*}{ Mode } & \multicolumn{2}{|c|}{ Thick } & \multicolumn{2}{|c|}{ Thin } & \multirow{2}{*}{ p value } \\
\hline & $\mathbf{N}$ & $\%$ & $\mathbf{N}$ & $\%$ & \\
\hline CS & 25 & 64.1 & 43 & 34.7 & \multirow{3}{*}{$0.001 *$} \\
\hline VD & 14 & 35.9 & 81 & 65.3 & \\
\hline Total & 39 & 100 & 124 & 100 & \\
\hline
\end{tabular}

*: significant at $5 \%$ level of significance $(\mathrm{p}<0.05)$.

Table 5: Association of mode of delivery with nicu stay in MSAF.

\begin{tabular}{|c|c|c|c|c|c|c|}
\hline \multirow{2}{*}{ Duration of NICU stay } & \multirow{2}{*}{ Mode of delivery } & \multicolumn{2}{|c|}{ Thick } & \multicolumn{2}{|c|}{ Thin } & \multirow{2}{*}{ P value } \\
\hline & & $\mathbf{N}$ & $\%$ & $\mathbf{N}$ & $\%$ & \\
\hline \multirow{4}{*}{$\leq 24$ hours } & $\mathrm{CS}$ & 15 & 57.7 & 39 & 33.6 & \multirow{4}{*}{$0.047 *$} \\
\hline & VD & 10 & 38.5 & 75 & 64.7 & \\
\hline & Instrumental & 1 & 3.8 & 2 & 1.7 & \\
\hline & Total & 26 & 100 & 116 & 100 & \\
\hline \multirow{4}{*}{$>24$ hours } & $\mathrm{CS}$ & 10 & 76.9 & 4 & 50 & \multirow{4}{*}{0.199} \\
\hline & VD & 2 & 15.4 & 4 & 50 & \\
\hline & Instrumental & 1 & 7.7 & 0 & 0 & \\
\hline & Total & 13 & 100 & 8 & 100 & \\
\hline
\end{tabular}

*: significant at $5 \%$ level of significance $(\mathrm{p}<0.05)$. 
The fetal heart rate variabilities were noted on cardiotocography test (CTG) and had significant correlation with $\mathrm{p}$ value of 0.030 , with maximum cases having abnormal fetal heart rate pattern in thick MSAF (Table 3; Figure 2).

Maximum cases with thin meconium had vaginal delivery $(65.3 \%)$, while patients with thick meconium had either instrumental delivery (3) or caesarean section $(64.1 \%)$, which was statistically significant with $\mathrm{p}$ value of 0.001 (Table 4).

Incidence of caesarean section and operative vaginal delivery was more in thick MSAF in our study. More number of cases with thin meconium had less stay in NICU compared to thick meconium who underwent caesarean section and had longer NICU admission (Table 4 and 5).

\section{DISCUSSION}

Assessment of the fetal wellbeing in labour is done by fetal heart rate (FHR) monitoring and by knowing the presence of meconium in the amniotic fluid. ${ }^{14,15}$ Meconium stained amniotic fluid seen in breech presentation is of no significance as it is due to mechanical compression on the fetal abdomen, but the MSAF in cephalic presentation is of greater concern. ${ }^{16}$ The rate of MSAF varies from $12-16 \% .^{1-3}$

In present study the incidence of MSAF was $12.9 \%$, which was comparable with the study done by Priyadharshini MV et al giving the incidence of $11.77 \%$ and Sori DA et al, with incidence of $15.4 \%$ respectively. ${ }^{13,17}$ But, the incidence was high in study conducted by Samiyappa DP et al, giving an incidence of $23.6 \%$ (Table 1). ${ }^{16}$ The incidence of both thin and thick MSAF in primigravida being 67(41.1\%) and multigravida 96(58.8\%) respectively, but in a study done by Akhila $S$ et al, the incidence of MSAF was more in primigravida $190(54.6 \%)$ and Tayade S having incidence of $71.66 \%$ in primigravida and $28 \%$ in multigravida (Table 1). ${ }^{18,19}$ Present study showed maximum cases i.e., 115(70\%) with MSAF seen in gestational age $\geq 40$ weeks, which was comparable with studies conducted by Mudhra $\mathrm{R}$ et al, having $50 \%$ incidence; Desai DS et al, giving an incidence of $63.96 \%$ and Fischer $\mathrm{C}$ et al, showing maximum cases seen in post-dated pregnancy respectively (Table 1). ${ }^{20-22}$ Stage of labour at which the MSAF was diagnosed was in active stage with thin meconium (75.8\%), which is comparable with study done by Qadir S et al, giving incidence of 70.37\% (Table 1). ${ }^{6}$ In present study the antenatal complications are more associated with thin meconium stained liquor compared to other deliveries with no meconium (Figure 1).

According to Priyadharshini MV et al, the antenartal complications associated with MSAF were pregnancy induced hypertension (PIH) 12; post-dated pregnancy 82 , oligohydromnios 9 , gestational diabetes mellitus 8 ; heart disease 5; high maternal age 5; chronic respiratory disease 4 and teenage pregnancy 5 cases. ${ }^{13}$ In present study thick and thin MSAF cases associated with abnormal FHR patterns on CTG were $17.1 \%$ and $34.3 \%$ respectively.

Similar studies done by Desai D et al, and Fischer C et al, showed abnormal FHR pattern in $34.66 \%$ and $49.4 \%$ respectively indicating that abnormal FHR pattern is seen more with MSAF (Table 2). ${ }^{22,23}$ The cases with thick MSAF needed more of operative interference in the present study giving an incidence of $64.1 \%$, whereas the incidence of vaginal delivery was more with thin MSAF $81(65.3 \%)$ showing stastical significance with $\mathrm{p}$ value of 0.001 (Table 2). Studies done by Qadir $\mathrm{S}$ et al, and Priyadharshini MV showed comparison with present study showing higher incidence of caesarean with thick MSAF (69.35\%) and vaginal delivery $(53.48 \%) .{ }^{6,13}$ But study done by Desai DS et al, had higher incidence of caesarean section (86\%) compared to present study. ${ }^{21}$

Correlation of thick and thin MSAF with Apgar score at 1 and $5 \mathrm{~min}$ is statistically significant with p value of 0.003 and 0.001 respectively (Table 2). This is comparable with studies done by Qadir S et al, and Mundhra R et al, both showing statistical significance of $<0.001 .6,20$ But study done by Desai DS et al, showed that there was no much difference between Apgar at 1 and 5 minutes. ${ }^{21}$ In the present study, there only 2 cases had meconium aspiration syndrome (MAS) with thick MSAF giving incidence of $5.1 \%$ showing statistical significance with $\mathrm{p}$ value of 0.011 (Table 2), which was similar to studies done by Desai $\mathrm{D}$ et al, and Priyadarshini MV having incidence of $6 \%$ and $5 \%$ respectively and low incidence of $2.01 \%$ in a study done by Akhila $S$ et al. ${ }^{13,18,23}$ Thus, showing that the incidence of MAS is not directly associated with thin or thick MSAF. Neonates admitted to NICU for $>24$ hours were more with thick MSAF i.e., $33.3 \%$ with a $p$ value of $<0.001$ showing high significance, which was similar to study done by Qadir S et al, having $46.7 \%$ of NICU admissions with thick MSAF. 6 But, study done by Priyadarshini MV had incidence of only $14 \%$, which was very low compared to present study (Table 2). ${ }^{13}$

\section{CONCLUSION}

Present study showed that thick meconium is associated with more complications like increased operative interference, birth asphyxia, meconium aspiration syndrome, low Apgar score, prolonged NICU stay and overall increased perinatal mortality compared to thin meconium stained liquor. As the gestational age increased the incidence of meconium increased and a greater number of thick meconium had abnormal CTG.

Funding: No funding sources

Conflict of interest: None declared

Ethical approval: The study was approved by the Institutional Ethics Committee 


\section{REFERENCES}

1. Maymon E, Chaim W, Furman B, Ghezzi F, Shoham Vardi I, Mazor M. Meconium stained amniotic fluid in very low risk pregnancies at term gestation. Eur $\mathrm{J}$ Obstet Gynaecol Reprod Biol. 1998;80:169-73.

2. Wiswell TE, Henley MA. Intratracheal suctioning, systemic infection and the meconium aspiration syndrome. Paediatr. 1992;89:203-6.

3. Cleary GM, Wiswell TE. Meconium-stained amniotic fluid and the meconium aspiration syndrome - An update. Paediatr Clin North Am. 1998;45:511-29.

4. Steer PJ, Eigbe F, Lissauer TJ, Beard RW. Interrelationships among abnormal cardiotocograms in labor, meconium staining of the amniotic fluid, arterial cord blood $\mathrm{pH}$, and Apgar scores. Obstet Gynaecol. 1989;74:715-21.

5. Ahanya SN, Lakshmanan J, Morgan BL, Ross MG. Meconium passage in utero: mechanisms, consequences, and management. Obstet Gynaecol Survey. 2005;60:45-56.

6. Qadir S, Jan S, Chachoo JA, Parveen S. Perinatal and neonatal outcome in meconium stained amniotic fluid. Int J Reprod Contracept Obstet Gynecol. 2017;5(5):1400-5.

7. Mukhopadhyay PN, Naskar T, Dalui R, Hazra S, Guin K. Role of intrapartum amnioinfusion in meconium stained amniotic fluid. J Obstet Gynaecol India. 2006;56(3):230-2.

8. Hackey WE. Meconium Aspiration. In: Gomella TL, ed. Neonatology. $4^{\text {th }}$ ed. New York: Lange Medical Books; 1999:507.

9. Shaikh EM, Mehmood S, Shaikh MA. Neonatal outcome in meconium stained amniotic fluid-one year experience. J Pak Med Assoc. 2010;60:711-4.

10. Ashfaq F, Shah AA. Effect of amnioin fusion for meconium stained amniotic fluid on perinatal outcome. J Pak Med Assoc. 2004;54:322-5.

11. Steer PJ, Daniethian P. Foetal distress in labour. In: James DK, Steer PJ, Weiner CP, Gonaik B, eds. High risk pregnancy: management options. $3^{\text {rd }}$ ed. Philadelpia: Elsevier Inc; 2006:1450-1472.

12. Tybulweicz AT, Clegg SK, Fonte GJ, Stenson BJ. Preterm meconium staining of the amniotic fluid: associated finding and risk of adverse clinical outcome. Arch Dis Child Foetal Neonatal Ed. 2004;89:F328-30.
13. Priyadharshini M, Panicker S. Meconium stained liquor and its fetal outcome-retrospective study. IOSR-JDMS. 2013;6(2):27-31.

14. NICE, intrapartum guideline 55, London: national institute for health and clinical excellence, 2007. Available at: https://www.nice.org.uk/guidance/cg55.

15. Gee H. Routin interpartum care; an overview. In: Luesley DM, Baker PN, eds. Obstetrics and gynecology: an evidence based test for MRCOG, $2^{\text {nd }}$ ed. Hodder Arnold; 2010:287-95.

16. Samiyappa DP, Ghose S, John LB, Samal R. Maternal and perinatal outcome in meconium stained amniotic fluid at term: a case control study. Int J Reprod Contracept Obstet Gynecol. 2016;5(10):3404-10.

17. Sori DA, Belete A, Wolde M. Meconium stained amniotic fluid: factors affecting maternal and perinatal outcomes at Jimma University specialized teaching hospital, South West Ethiopia. Gynecol Obstet (Sunnyvale). 2016;6(394):2161-932.

18. Akhila S, Koppad AM, Aundhakar CD. Study of neonatal outcome in meconium stained amniotic fluid. Int J Med Health Res. 2018;4(3):134-8.

19. Tayade S. The significance of meconium stained amniotic fluid-a cross sectional study in a rural setup. Int J Biomed Adv Res. 2012;3(12).

20. Mundhra R, Agarwal M. Fetal outcome in meconium stained deliveries. J Clin Diagnos Res: JCDR. 2013;7(12):2874-6.

21. Desai D, Maitra N, Patel P. Fetal heart rate patterns in patients with thick meconium staining of amniotic fluid and its association with perinatal outcome. Int $\mathbf{J}$ Reprod Contracept Obstet Gynecol. 2017;6(3):10305.

22. Fischer C, Rybakowski C, Ferdynus C, Sagot P, Gouyon JB. A population-based study of meconium aspiration syndrome in neonates born between 37 and 43 weeks of gestation. Int J Pediatr. 2011;2012.

23. Desai D, Chauhan K, Chaudhary S. A study of meconium stained amniotic fluid, its significance and early maternal and neonatal outcome. Int J Reprod Contracept Obstet Gynecol. 2016;2(2):190-3.

Cite this article as: Biradar A, Kori S, Patil N, Mudanur SR. Meconium stained liquor and perinatal outcome. Int J Reprod Contracept Obstet Gynecol 2018;7:5056-60. 